\title{
5-axis High Speed NURBS-machining on a new parallel kinematic-machine
}

\author{
Volker Kreidler
}

Siemens Automation \& Drives, Business Development Unit

\section{PROCESS OF HYDROFORMING TOOL PRODUCTION}

On CAD-level the hydroforming tool was designed by using drawing simulation software tools to make shure that the drawing process works. CAD-data is communicated to the NCProgramming system where the planning of the machining processes takes place. The milling strategy has to be selected. Tool path generation with the right cutters, all cutting parameters such as feedrate, spindle speed, depth of cutting are done by the NC-programming system. CNC-machining is the milling process where the final tool is created. After the final workpiece is available the quality of the part has to be evaluated. In the field of free form surface parts such as hydroforming parts different measuring methods can be applied. Typically the part is measured on a coordinate measuring machine. The part is probed along a couple of cross sections. The resulting polygone can then be checked against the CADoriginal. More sophisticated methods are taking millions of surface points with optical sensors. Based on this points a surface is then mathematically re-engineered for the purpose of comparison against the original $\mathrm{CAD}$-surfaces.

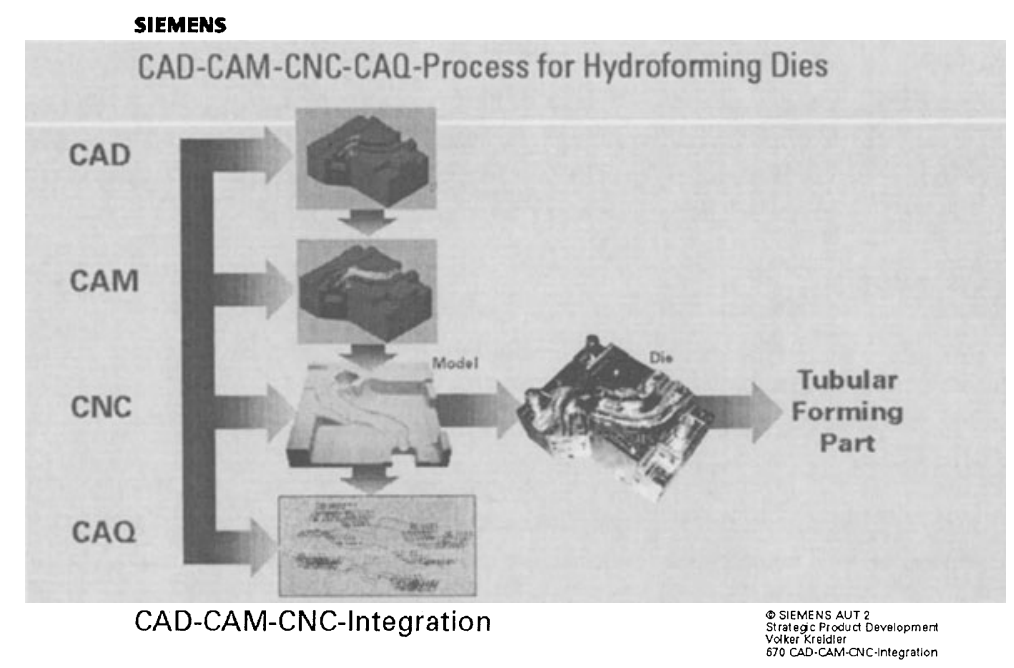

Figure 1. CAD-CAM-CNC-process for hydroforming tools

\section{PROBLEMS OF CONVENTIONAL NC-PROGRAMMING}

While CAD-systems provide very sophisticated mathematical capablilities to represent geometry for free form surfaces such as Bezier-Splines and NURBS, CAM-systems and conventional CNC-controllers don't. CAM-systems create by their NC-generation the tool path point by point. This creates for the $\mathrm{CNC}$-controller a sequence of linear blocks. Even if new CAM-methods would generate higher level geometrical representations conventional CNC-technology would not be able to handle this data.

The original version of this chapter was revised: The copyright line was incorrect. This has been corrected. The Erratum to this chapter is available at DOI: 10.1007/978-0-387-35392-0_40 


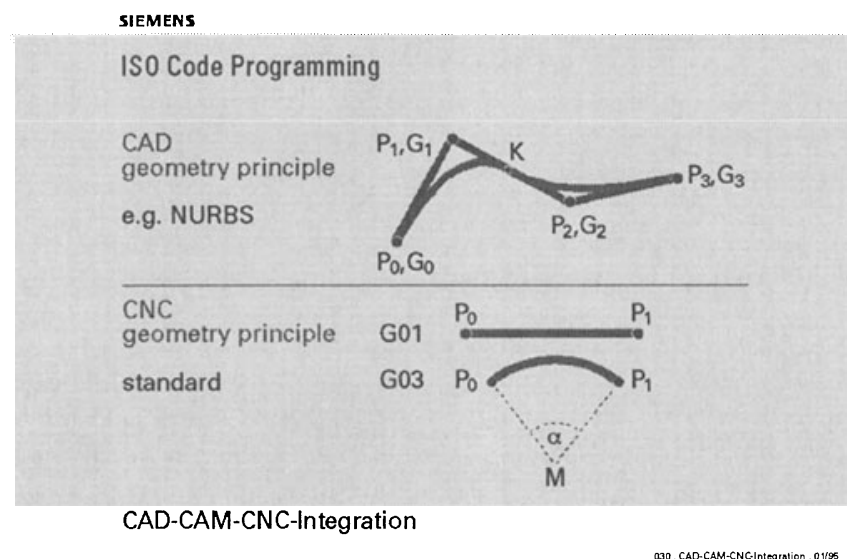

Figure 2: ISO code programming

Especially in the field of mould and die machining the user expects a high volumetric accuracy in the range of $1-2 / 100 \mathrm{~mm}$ and on top of this very smooth surface quality. The figure shows a red contour which is considered as the original tool path created by a cross section through the CAD-surface. But this line is represented by a polygone and this cretaes a series of subsequential problems.

First of all the original surface of the workpiece is not exactly represented. This means that a path error is introduced even before the machine starts to move. The more curvature we have the more linear blocks are required to model the tool path within a given tolerance band. CNC-controllers have a given performance to process these blocks. So this situation can easily create computing limitations with the consequence that the controller has to reduce the path velocity.

\section{SIEMENS}

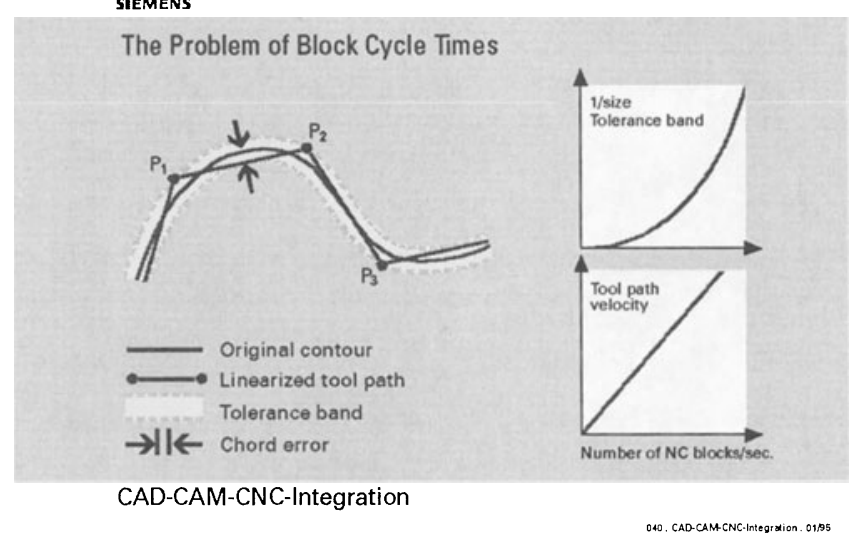

Figure 3. The problem of block cycle times

Today we are introducing high speed machines. We at Siemens have realized already milling machines but also Parallel Kinematic machines which are operating at $5 \mathrm{~g}$ acceleration. This is about 10-20 times faster than conventional machines. Using the same old way of representing the tool path by linear blocks the required block cycle times go in the range of sub-milliseconds. Increasing requirements are also the volumetric accuracy. The example I 
have presented at the beginning is a hydroforming die. Because of hydroforming process requirements the volumetric accuracy must be very good. This means for NC-programming that the tolerance band is getting tighter which again shortens the linear blocks and requires shorter cycle times. This dilemma can only resolved by replacing this very primitive method of representing the path geometry on CAM- and CNC-level by more sophisticated methods such as spline representations.

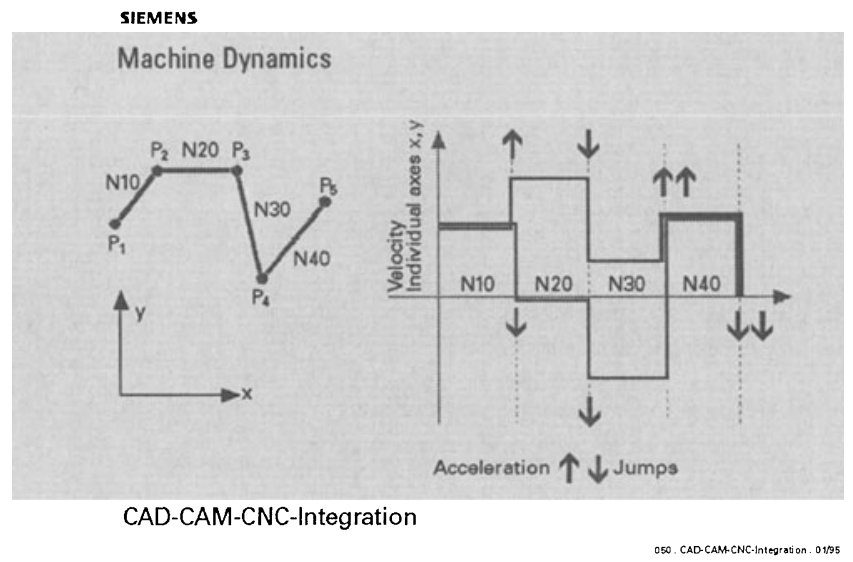

Figure 4. Machine dynamics

The picture shows a very primitive 2-dimensional tool path. A CNC-controller has to deduct out of this path the velocity profile of both participating machine axes. The result are two rectangular velocity profiles which have the meaning that the machine is required to perform at infinite acceleration and decceleration. This is impossible to a mechanical system. As a consequence the controller calculates tricky profiles to avoid the problems with the result of lack of productivity and severe problems on cutting conditions.

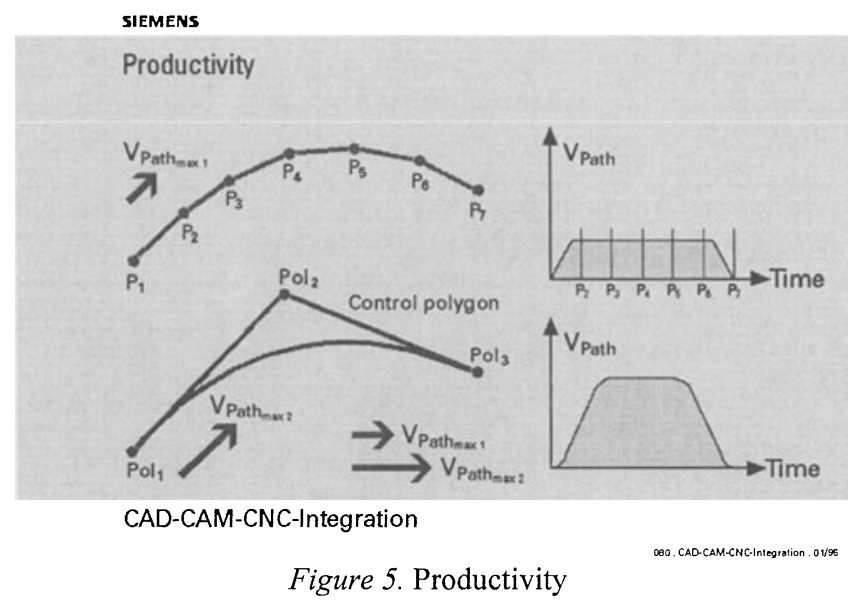

The figure shows two different tool path representations. One is the old way of sequencial linear blocks. The other one is a smooth splinetype of curve. Because of non tangent transitions of the polygone the $\mathrm{CNC}$ has to deal with jumps of path velocity. This can only be treated by reducing the overall path velocity. Because the controller must avoid any 
mechanical damage to the machine. The smooth contour has tangent continuity and can be executed by the controller and the machine at a much higher average path velocity which means at the same time a much higher productivity.

\section{NON UNIFORM RATIONAL B-SPLINES (NURBS)}

During design and specification of the new Siemens controls technology we have introduced NURBS-technology by an objectoreinted way of implementation. We have not only a wide spectrum of spline methods realized we can even apply this spline features on all kind od variable treatment. While in the meantime some control vendors have also spline technology available this is in all cases limited to three axes. But especially when it comes to free form surface machining we must handle 5-axes of different machine configurations. But even more important is the fact that we can apply the spline methods on other variables than just the tool path interpolation. For example we can program the feedrate also by spline technology.

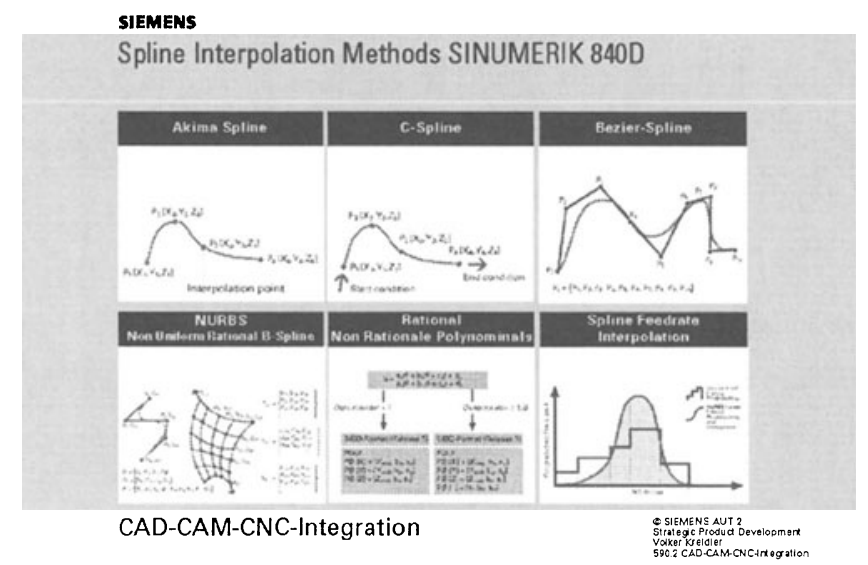

Figure 6. Spline interpolation methods 840D

The figure shows four different Spline-Interpolation methods which can be applied: Akima, C-Spline, Bezier-Spline and NURBS. In addition to this we have agreed with most of the $\mathrm{CAD} / \mathrm{CAM}$-suppliers that it is more efficiant to represent curves by rational polynomials. This interface format is used within most of our current applications. The last figure is the spline based programming and interpolation of the feedrate which is very unique and can create very good surface qualities.

By applying NURBS-technology over almost 4 years in a wide spectrum of applications we have also developed two very practical software tools for the users. Because most of the CAM-system still don't provide Spline-data as the tool path representation the Siemenscontroller can read conventional NC-data in a linear form and converts this data in real time into spline data. By the help of this tool the controller is compatible to existing NCprogramming code.

The second software tool is for offline programming and is named "Speedmill". This tool does in a very sophisticated way the conversion of conventional linear programming into Spline-format.

\section{NURBS-TEST MACHINING BY VOLVO}


The Swedish Volvo Corporation did end of 1996 serious evaluation tests regarding spline programming methods. Volvo designed a very critical test part by CATIA.

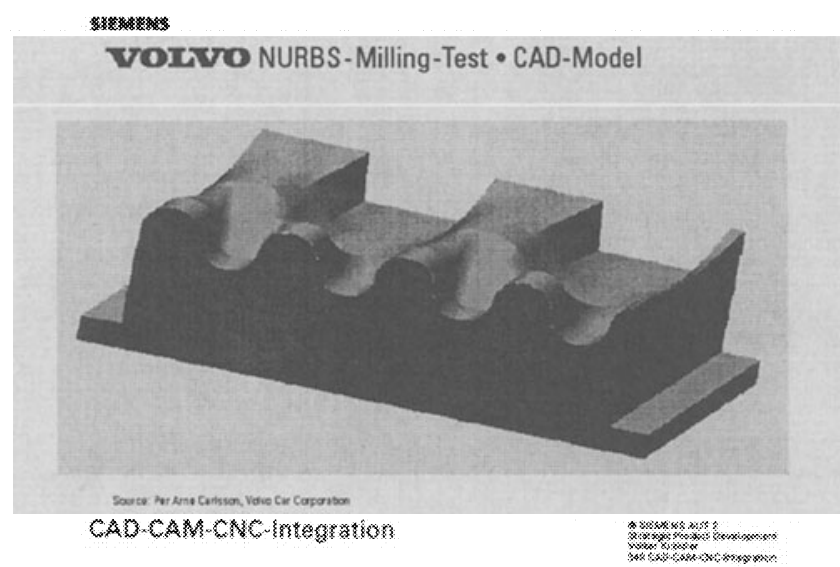

Figure 7. VOLVO NURBS-milling-test $\bullet$ CAD-model

The part was machined in aluminum and not in steel because they wanted to eliminate potential cutting limitations. The interest was only the influence of spline interpolation. The final part is shown on the next figure:

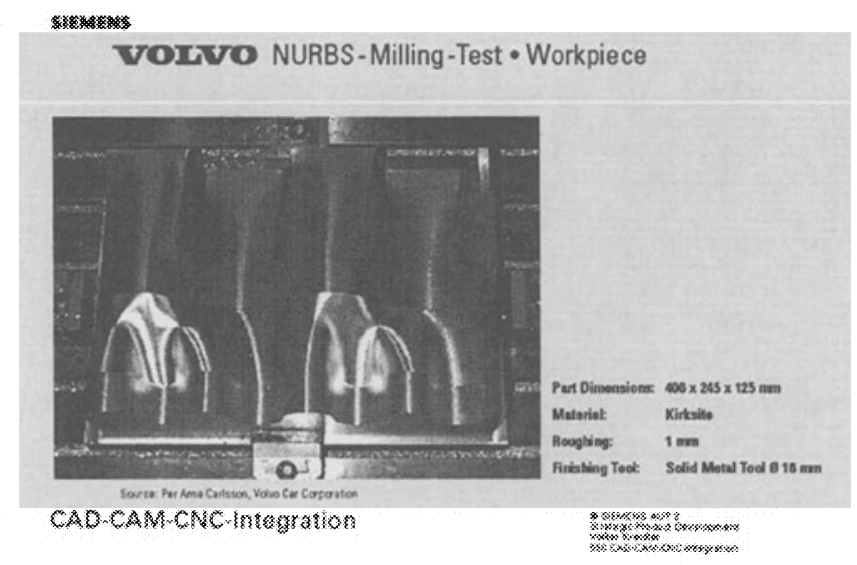

Figure 8. VOLVO NURBS-milling-test • workpiece

The evaluation criterias were the total machining time or the average feedrate but also the size of the NC-programs and finally the overall volumetric accuracy.

The first milling test was cutting the part by using the original conventional NC-program based on linear-point based programming. The second test was executed after the point based program was converted into splines.

The main result was that the machining time was reduced by Splines from $240 \mathrm{~min}$ to 120 min which means that the productivity was just doubled. The same statement can be expressed by the increase of the average feedrate from about $1 \mathrm{~m} / \mathrm{min}$ to $2 \mathrm{~m} / \mathrm{min}$. The size of the conventional program was about 180.000 NC-blocks while the Spline-program was only 50.000 blocks. 


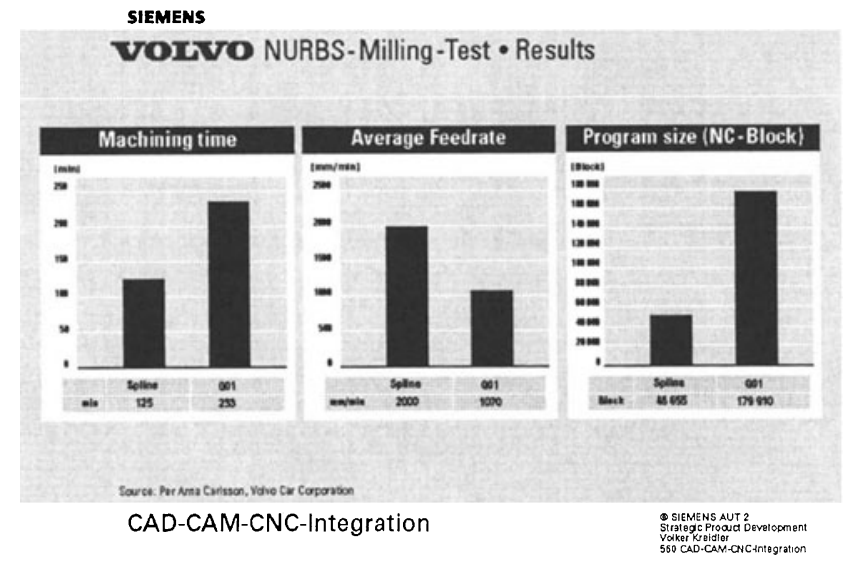

Figure 9. VOLVO NURBS-milling-test $•$ results

The measurements on the CMM-machine resulted in a better volumetric accuracy and a much smoother surface quality which is especially for tool and die applications very important.

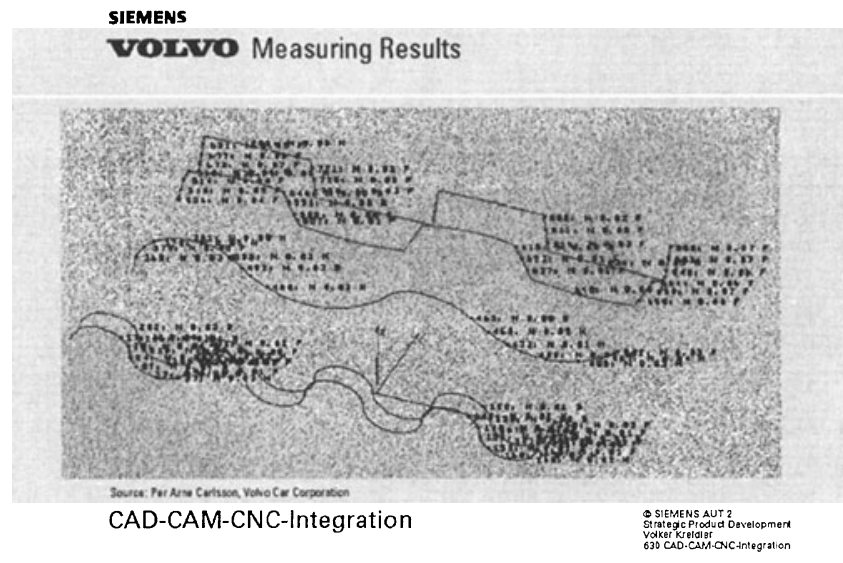

Figure 10. VOLVO NURBS-milling-test • measuring results

\section{PARALLEL KINEMATIC MACHINES}

Parallel Kinematic Machines (PKM's) came up as prototypes the first time on the International Machine Tool Show in Chicago 1994. Three machines were presented by the companies: Giddings\&Lewis, Ingersoll and Geodetic. Since this time Siemens is doing serious development work on this new technology. After some years of experimenting with different prototypes we have now the first series production machines available.

The term "parallel" means that a parallel kinematic machine is constructed only out of axes which carry only themselves. While in conventional serial mechanical designs axes are carrying each other. Imagine a simple 3-axes mill. One axes sits on top of the other. This creates high masses even if only little movement of the machine takes place. 


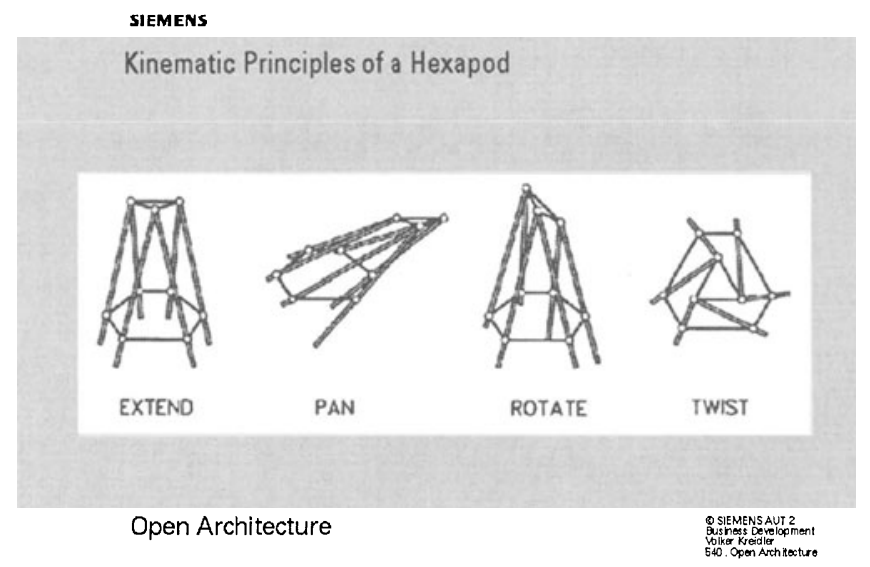

Figure 11. Kinematic principles of a hexapod

The figure shows the kinematic principle of a parallel machine. In this case we have a Hexapod-machine because the machine is composed out of 6 legs or struts. A strut is a telescopic leg which can change its length. In the figure 6 legs are attached to the ground through 6 sphere joints. On the other side 6 struts end in three sphere joint. (This is for example the design of Geodetic). If all 6 struts are stretching out in the same way the upper triangle which is also called the spindle platform will move in $+Z$-direction. If the struts of the left side are stretching out more than the struts on the right side the spindle platform moves to the right and can also change its orientation. Imagine a spindle motor and a cutter mounted on the upper platform we have already a milling machine. If this machine starts cutting forces are created. This forces are then introduced to all the 6 struts and each strut is by itself and not carrying other axes. That's "Parallel".

There are serious advantages of Parallel Machines. The fact of independent axes the machine can be built much lighter. The total moving mass can be drastically reduced and this creates the ability of a very high dynamic. Also a benefit of the Parallel design is the fact that the base structure is very stable and stiff so again weight can be reduced. From the cost side if the designer of the machine does it right - the machines will end up much cheaper because identical parts can be applied and manufacturing is reduced to a simple assembly process.

The video shows most Parallel Kinematic Machine projects which have been realized during the last years. Most of this examples are done by my own Business Development team.

\section{NEOS TRICEPT MACHINING CENTER TMC 805}

Neos is a Swedish company and is working on their patented so called Tricept-technology since the late eighties. Three years ago Neos have introduced their first Tricept-machine which is a machine for robotics applications and light milling. Together with Siemens a new Generation of Tricepts was developed during the last two years the Tricept Machining Center TMC 805.

The machine is a hybrid machine in the sense that three struts built a kernel Tripod machine. Attached to the spindle platform two additional rotary axes are added in a serial way. In the middle of the machine is the so called Center Tube which is based on the Neos patent. The central tube takes resulting moments and protects the machine against twisting and bending. 


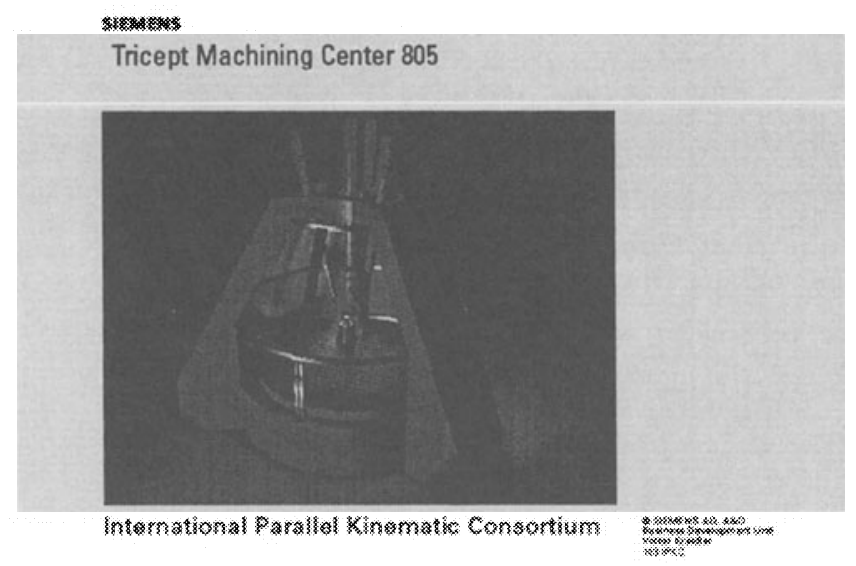

Figure 12. Neos tricept

This machine configuration is for heavy milling. Therefore the Tricept-module is attached to three columns which make this set up extremely stiff. We have here stiffness in Z-direction of $150 \mathrm{~N} /$ Mikron and in the X-Y-direction $90 \mathrm{~N} /$ Mikron. The working envelope is $2.5 \mathrm{~m}$ of rotary table and $800 \mathrm{~mm}$ in the Z-direction. The machine operates at up to $100 \mathrm{~m} / \mathrm{min}$ path velocity and over $2 \mathrm{~g}$ path acceleration. The typical spindle is from IBAG at $45 \mathrm{KW}$ and up to $24.000 \mathrm{rpm}$ 's at constant torque. The volumetric accuracy is in the average $+/-2 / 100 \mathrm{~mm}$.

We have developed a new regulation and error compensation approach together with Neos. This recently patented new methods give us the capability of auto-calibration and also real time errors compensation by using the so called direct measuring system:

The basic idea behind is that whatever machine errors occure statically and dynamicaly the total error will be visible by watching the central tube of the machine. Therefore we are using the three measuring systems of the Central Tube as the feedback for position loop and velocity control.

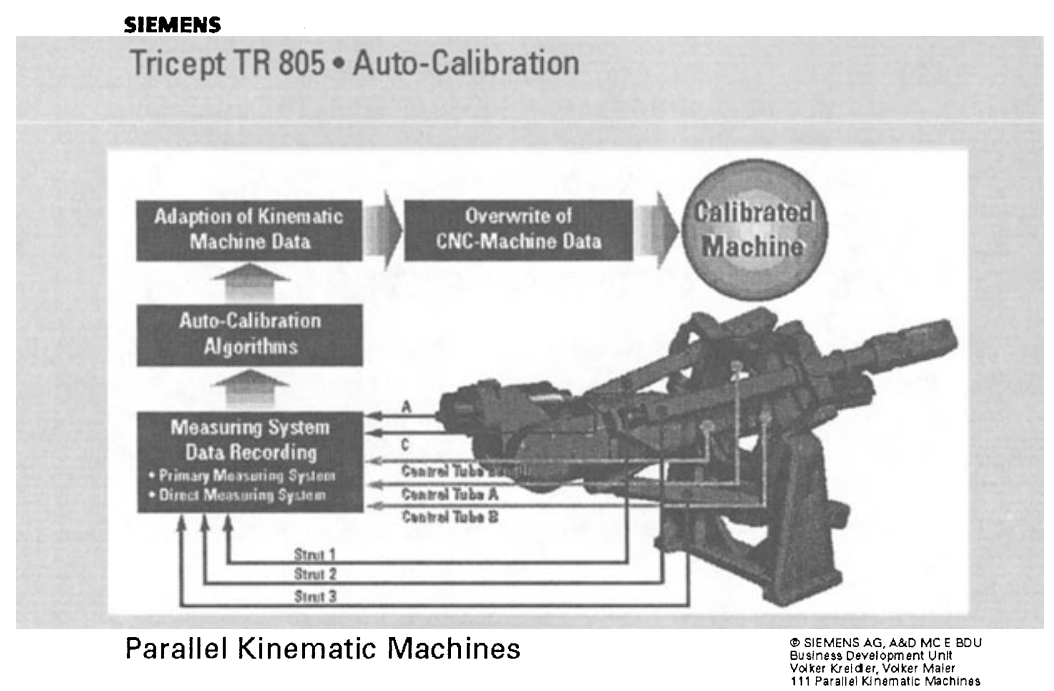

Figure 13. Tricept TR $805 \cdot$ auto calibration 


\section{MACHINING HYDROFORMING TOOLS ON TRICEPT MACHINE}

Between October 27 and 29 the first machining test for a SMG-Schäfer tubular forming die took place on the new TMC805 Tricept-machine. This test cut was done in Uriol-material because we wanted to have a model first for measuring purposes without cutting limitations caused by a steel die.

\subsection{Test Workpiece}

The die on the picture is the lower half of a tubular forming die. The dimensions are about 600 by $600 \mathrm{~mm}$. The forming area is visible in the center of the part and is a s-curved channel. This is the forming zone where the blank comes in.

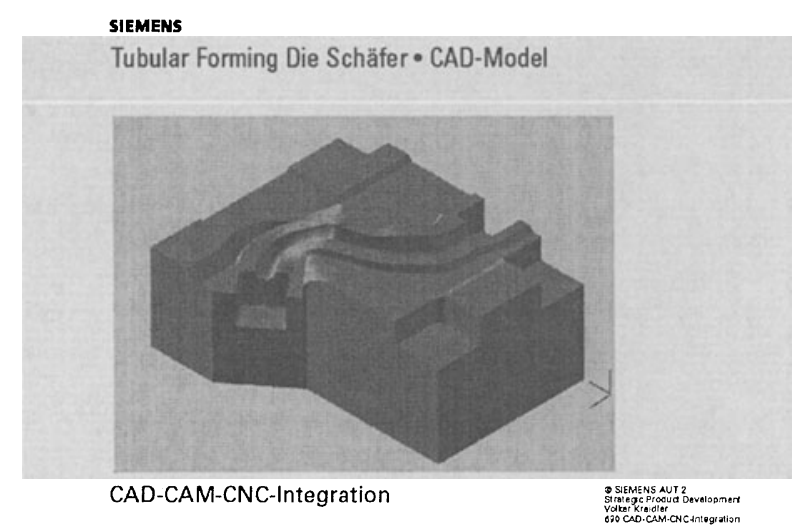

Figure 14. Tubular forming die Schäfer • CAD-model

\subsection{Machining Results}

The machining time of a conventional Gantry-machine was 64 hours in steel. This was done on what is called "latest technology" 5-axes milling machine and the volumetric accuracy was in the range of $+/-1 / 10 \mathrm{~mm}$. Our machining test was done in Uriol because we wanted to find out first the machine capabilities without speed reductions caused by cutting limitation sof steel.

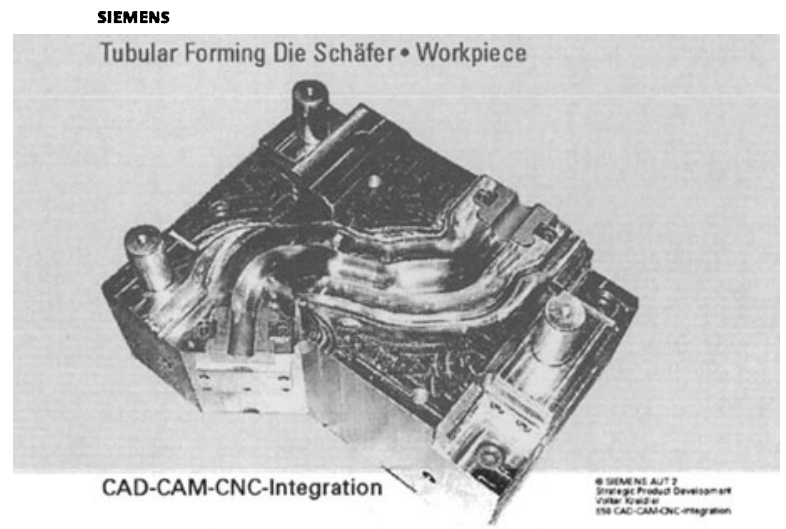

Figure 15. Tubular forming die Schäfer • workpiece 
This are the results:

\begin{tabular}{|c|c|c|c|c|c|c|}
\hline Feedrate & Roughing & $\begin{array}{c}\text { Roughing } \\
\text { Spline }\end{array}$ & $\begin{array}{c}\text { Finishing } \\
\text { Linear }\end{array}$ & $\begin{array}{c}\text { Finishing } \\
\text { Spline }\end{array}$ & $\begin{array}{c}\text { Total } \\
\text { Machining } \\
\text { Linear }\end{array}$ & $\begin{array}{c}\text { Total } \\
\text { Machining } \\
\text { Spline }\end{array}$ \\
\hline $1.5 \mathrm{~m} / \mathrm{min}$ & $5.1 \mathrm{~h}$ & - & $2.1 \mathrm{~h}$ & $1.6 \mathrm{~h}$ & $7.2 \mathrm{~h}$ & $6.7 \mathrm{~h}$ \\
\hline $7 \mathrm{~m} / \mathrm{min}$ & $1.1 \mathrm{~h}$ & - & $0.85 \mathrm{~h}$ & $0.35 \mathrm{~h}$ & $1.95 \mathrm{~h}$ & $1.45 \mathrm{~h}$ \\
\hline $20 \mathrm{~m} / \mathrm{min}$ & $0.57 \mathrm{~h}$ & $0.4 \mathrm{~h}$ & $0.7 \mathrm{~h}$ & $0.17 \mathrm{~h}$ & $1.27 \mathrm{~h}$ & $0.57 \mathrm{~h}$ \\
\hline
\end{tabular}

The first conclusion is the fact that spline programming cuts down the time consuming finishing by $50 \%$ in the area of $7 \mathrm{~m} / \mathrm{min}$ feedrate. If the machine can go faster what we did in the case of the TMC 805 we could cut down machining time by $80 \%$. Splines don't give us a lot at roughing and low speeds because there we have only a few NC-blocks. At higher speed up from $15 \mathrm{~m} / \mathrm{min}$ even for roughing we could reduce the speed by splines.

The following video sequence shows the test machining which happened two weeks ago in Stockholm, Sweden.

The Tricept TMC 805 we have used for this test series is a one column machine which is for soft materials. This machine is limited to $25 \mathrm{~m} / \mathrm{min}$ and about $1 \mathrm{~g}$ acceleration. In the week 49 we will do the same test cuts again in Uriol and steel on the three column TMC 805. With this machine we can double the average feedrate again.

We will get of course longer machining times than shown above because steel will present limitations of the cutting speed. It is already clear that the dynamic of this new Tricept machine will only be reduced by the capabilities of the cutters and the spindle.

The first series of measurements of the Uriol part was done on a CMM-machine two weeks ago and we found good results regarding volumetric accuracy. The average was in the range of $+/-1 / 10 \mathrm{~mm}$. The tests where we have used spline interpolation show a much better surface accuracy. In other words the surface is smoother and will reduce the manual finishing operations.

This first test machining of hydroforming dies were done for SMG. This is part of their evaluation to decide if the Tricept technology will be used for their future die machining. According to the presented results the decision will be positive and the first TMCs will be set up at SMG-Schäfer's model factory in Wilnsdorf Germany around April. We are already working together with SMG-Schäfer on two other Tricept-applications. One is for measuring and one for laser cutting.

Germany around April. We are already working together with SMG-Schäfer on two other Tricept-applications. One is for measuring and one for laser cutting.

The following video sequence shows the test machining which happened two weeks ago in Stockholm, Sweden.

\section{CONCLUSION}

I was presenting the problems of conventional NC-programming when it comes to machining of free form surface parts such as hydroforming dies. New Spline-technologies where introduced which improve the productivity and the volumetric and surface accuracy.

A complete new mechanical approach was presented. The Parallel Kinematic Triceptmachine by the Swedish company Neos and the test we have done just two weeks ago. The results show that this machine technology will have a very positive future because of its high dynamic and productivity.

I can imagine that when you come to SMG-Schäfer's hydroforming model factory next year you can see this new machines in action. 